\title{
REVIEW
}

\section{Cancer gene and immunotherapy: recent developments}

\author{
Peter Jantscheff ${ }^{1}$, Richard Herrmann ${ }^{2}$ and Christoph Rochlitz ${ }^{2}$ \\ ${ }^{\prime}$ Department of Research/Molecular Cancer Research; ${ }^{2}$ Division of Medical Oncology, Kantonsspital, Basel, \\ Switzerland
}

\begin{abstract}
Gene and immunotherapeutic approaches to treat human malignant tumors are reviewed. Special attention is given to the different strategies of cancer gene therapy and to recent aspects of cytokine-supported tumor immunotherapy or tumor-specific vaccination. The limitations of these therapy approaches are critically discussed especially with respect to immune escape mechanisms.
\end{abstract}

Keywords: tumour; gene therapy; immunotherapy; cytokines; escape; melanoma; review

\section{Gene therapy of cancer}

In recent years various gene therapeutic approaches to the treatment of human cancer have been developed and over 300 clinical protocols have already been approved. ${ }^{1.2}$ Three main categories of somatic cell gene therapy can be identified. ${ }^{2}$ First, cells are removed from the body or obtained from tissue culture, transfected $e x$ vivo with a vector and reinfused after gene engineering into the patient. ${ }^{3}$ Second, the vector is placed directly in situ into affected tissues, eg the lung or a tumour mass, of the patient. ${ }^{2}$ Third, is an in vivo therapy, whereby the vector is injected directly into the blood stream. At present there are only clinical examples of the first two categories. In these studies, the genes were transferred into target cells either by lipofection, electroporation or naked DNA technique using classic eukaryotic expression vectors, eg based on SV40 or cytomegali virus (CMV), or viral vectors based on RNA (eg MuLV), or DNA viruses (eg of adeno or poxvirus families). ${ }^{2}$

Correspondence: Peter Jantscheff PhD, Kantonsspital Basel, Department of Research/Molecular Cancer Research-Room 301, Hebelstr. 20, CH-4031 Basel, Switzerland. Tel: 0041612652354 ; Fax 0041612652350 ; E-mail: jantscheff@ubaclu.unibas.ch

Received 13 January 1999; accepted 10 February 1999
Using these tools, gene cancer therapy tries to intervene at different molecular or physiological levels of the malignant tumour cell development. One approach attempts to infect cancer cells with intact tumour suppressor (eg p53) or anti-oncogenes, and to use, respectively, antisense oligonucleotides or intracellular recombinant single chain antibodies to inhibit activated oncogenes (eg $c-m y b$, erbB2) $)^{4-7}$ Other strategies try to modify cellular drug resistance (eg by wild type MDR cDNA) or to introduce 'suicide' genes, eg herpes simplex virus thymidine kinase (HSV-tk), into the tumour cells. ${ }^{8.9}$ A further approach, especially used in leukaemia and lymphoma patients, introduces gene markers (eg $\beta$-galactosidase, neomycin resistance) into blood or bone marrow cells to identify efficacy of purging and origin of relapse following autologous stem cell transplantation. ${ }^{10.11}$ The most commonly used concept (64/144 clinical protocols worldwide), however, tries to augment the immune system's capacity to eliminate autologous cancer cells by different approaches.

This is attempted by cytokine-supported immunotherapy, enhancing the tumour immunogenicity or tumour-specific vaccination and by combinations of the different approaches (see reviews of recent clinical protocols ${ }^{1,2}$ ). 


\section{Cytokine-supported immunotherapies}

The notion that cytokines such as interferons and interleukins can enhance the immunogenicity and induce reproducible responses also to spontaneous tumours led to increasing investigations and later clinical use. ${ }^{12-14}$ Clinical trials were started with systemic applications of interferons and interleukin-2 (IL-2). ${ }^{15,16}$ After administration of high doses of recombinant IL-2 to 283 consecutive patients (Surgery Branch at the National Cancer Institute: 1985-1992), complete responses were seen in patients with metastatic renal cell cancer $(9 \%)$ or melanoma patients (7\%). However, systemic IL-2 administration was associated with substantial toxicity (eg capillary leak syndrome). ${ }^{14}$ These side effects, including treatmentrelated mortality, could be diminished by cardiac screening of patients and the aggressive use of prophylactic antibiotics, but they remain a problem. ${ }^{14}$

The mechanism(s) by which cytokines support an anti-tumoural immune response are manifold. ${ }^{12.13}$ It was proposed that local rather than systemic cytokine effects mimic the natural cytokine physiology and are more likely to promote $\mathrm{T}$ cell responses against weak immunogenic tumour antigens, to activate non-specific killing (NK), lymphokine activated killer (LAK) cells, $\mathrm{Mo} / \mathrm{M} \Theta$, or to enhance tumour antigen presentation. This hypothesis was supported by rejection of tumours after repeated local administration of exogeneous cytokines in the vicinity of draining lymph nodes or directly into the tumour. ${ }^{17}$ In addition, numerous studies have shown that weakly immunogenic tumour cells could be altered to become targets for specific immune rejection by transfection with cytokine genes. The first experimental models and clinical applications carrying cytokine gene transfected malignant cells focused on IL-2. ${ }^{18-27}$ In most experimental systems, the expression of IL-2 by weakly immunogenic tumour cells resulted in growth inhibition of the modified tumour cells. In several cases, a systemic immune response against the parental tumour, leading to an immune memory against a challenge with parental tumour cells was also observed. ${ }^{19-21}$ The inhibitory effect was dose dependent and the degree of suppression of growth correlated directly with the amount of IL-2 produced by the tumour cells. In vaccination experiments, however, intermediate doses of IL-2 achieved highest cure rates in mice. ${ }^{28.29}$ Clinical trials treating advanced cancer patients with IL-2 secreting tumour cells showed a variable outcome of the therapy. Thus, tumour regression, stabilisation of the disease, mixed types of response with simultaneous evidence of regressing and non-responding lesions in the same patient or progressive tumour growth were noted. ${ }^{30-33}$ The evaluation of mechanisms involved in treatment with transfected tumour cells showed that IL-2 release in situ leads to a dense infiltration of the tumour involving mainly $\mathrm{CD}^{+}$and $\mathrm{CD} 8^{+} \mathrm{T}$ cells as well as NK cells. It was demonstrated that $\mathrm{CD}^{+} \mathrm{T}$ cells are essential for complete tumour rejection and long term protection against the original tumour ${ }^{19.34,35}$ and that IL-2 can bypass $\mathrm{CD}^{+} \mathrm{T}$ helper function in the generation of an anti-tumour response ${ }^{19}$ or can overcome cytotoxic T lymphocyte (CTL) anergy. ${ }^{36.37}$ The in vivo role of $\mathrm{NK}$ cells remains unclear but might be important especially in tumours with down regulated MHC class I molecules or in the absence of killer cell inhibitory receptors (KIR). ${ }^{38.39 .40 .41}$

Several other interleukins (IL-4, IL-7, IL-12, IL-13), interferons (IFN $\gamma, \operatorname{IFN} \alpha$ ), haematopoietic growth factors, granulocyte-macrophage colony-stimulating factors (GM-CSF, G-CSF, M-CSF), chemokines (MCP-1, TCA-3), and inflammatory mediators - tumour necrosis factor (TNF), IL-1, IL-6 - transfected in tumour cells showed similar tumouricidal effects mediated by different effector mechanisms. ${ }^{12,13}$ It was also demonstrated that cytokines can be protective against tumour growth if transfected into normal fibroblasts or when secreted by allo or xenogeneic cells with respect to the tumour and the host animal. ${ }^{13.38 .42}$ The concept of using cytokine-transfected allogenic and xenogenic tumour cells or fibroblasts instead of autologous/syngenic cells in the prevention and treatment of tumours was developed by several groups, eg by P Kourilsky at the Institut Pasteur in Paris. ${ }^{12}$ It included the transfection of different murine tumour cells with murine or human cytokines (IL-2, GM-CSF, IL-4, and IFN $\gamma$ ) or allogenic major histology complex (MHC) class I molecules $(\mathrm{H} 2-\mathrm{Kb}){ }^{12.38 .43}$ Using allo or xenogenic cytokinesecreting cells, it was demonstrated that this specific immunotherapeutical strategy was effective to control tumour growth in several mouse and rat models. ${ }^{12,38.43}$ This anti-tumour effect was mainly mediated by NK-cells. ${ }^{38}$ The results led to the initiation of a controlled study more closely mimicking the biology of human tumours. Treatment of spontaneous fibrosarcomas in cats and melanomas in dogs with xenogenic IL-2 transfected fibroblasts, the green monkey cell line 
(Vero-IL-2) (Transgène, Strasbourg) resulted in substantially improved disease free and overall survival. ${ }^{42}$

Although many questions remain to be answered, and only in some experimental systems was rejection of established disease achieved, ${ }^{42,44-49}$ the promising results obtained in animal studies have established the basic biological value of gene therapy with cytokinesecreting cells and these approaches are already widely used in clinical trials. ${ }^{1.13}$ More than $60 \%(26 / 43)$ of recent 'cytokine-supported' clinical cancer gene therapy trials use IL-2, whereas others utilise IL-4, IL-7, IL-12, IFN $\gamma$, GM-CSF, TNF or combinations thereof. ${ }^{1}$ One of the first cancer gene therapy trials initiated in Switzerland in January 1996 used the 'xenogenic approach'. ${ }^{12.42}$ In this study, three cohorts of three successive patients with advanced solid tumours accessible to CT or ultrasound-guided injection were treated intra-tumourally repeatedly with different doses of xenogeneic monkey fibroblasts secreting high doses of human IL-2 (Vero-IL-2). Endpoints of the study were feasibility, toxicity, and clinical and biological effects of this novel approach to immunotherapy of cancer. Treatment was well tolerated and toxicity consisted of transient fever in one patient and short-lived, mild itching and erythema in two others. One patient with soft tissue sarcoma showed a more than $90 \%$ and more than $50 \%$ reduction of the volume of two distant, noninjected metastases, lasting for $29+$ and 26 months, respectively. Four other patients showed stabilisation of their disease for 3-9 months, among whom was a patient with melanoma who developed marked vitiligo. Repeated injection of up to $5 \times 10^{7}$ Vero-IL-2 cells was thus feasible and safe in heavily pretreated patients with advanced solid tumours and showed signs of clinical and biological activity. ${ }^{33}$ Histopathological, immunological and molecular analyses were performed on biopsy specimens of tumours and blood samples obtained before, during and after treatment. Only a slight but statistically significant $(P<0.05)$ increase of serum IL-2 could be observed on day 5 of treatment which returned to base line values by day 15 . Also on day 5 , a significant increase $(P<0.05)$ in CD3 mRNA was detected in tumour biopsies by RT-PCR, indicating transient infiltration of injected sites by $T$ lymphocytes. ${ }^{33}$ No expression of exogenous IL-2 mRNA (ie of the transgene) could be detected by RT-PCR in tumour biopsies and peripheral blood of days 1,5 , and 15 , most likely reflecting rapid destruction of Vero cells by patient's NK cell-like killer cells.

\section{Melanoma antigens: recognition and vaccination}

An important prerequisite for the induction of a tumour-specific immune response is the MHC restricted $\mathrm{T}$ lymphocyte recognition ${ }^{50}$ of small antigenic peptides $^{50.51}$ from tumour-specific (TSA) or tumourassociated (TAA) antigens in tumour cells. ${ }^{52,53,54}$

To identify the antigenic peptides recognised by tumour-specific CTL on MHC class I molecules, mainly four methods have been used: transfection of recombinant tumour DNA libraries into cells expressing MHC presenting molecules, ${ }^{54}$ biochemical purification of peptides eluted from MHC molecules of the tumour cells, ${ }^{55}$ designing of consensus anchor motifs carrying candidate peptides from proteins known to be overexpressed or mutated in tumour cells ${ }^{56}$ or screening of cellular immune response to SEREX-defined (serological analysis of tumour antigens by recombinant cDNA expression cloning) tumour antigens. ${ }^{57,58}$

Based on the pattern of expression of the parent protein and tumour specificity, the antigens can be classified into five major groups:

i) antigens resulting from mutations, ${ }^{59,60}$

ii) viral antigens, ${ }^{61}$

iii) tumour-specific shared antigens of the 'cancer testis' gene family, ${ }^{62,63}$

iv) over expressed antigens ${ }^{64.65}$, and

v) tissue-specific differentiation
antigens.

(TSDA)

The number of tumour-specific mutated neoepitopes (eg in melanoma, renal cell cancer) or viral antigenic peptides (eg in cervical cancer, hepatomas) recognised by human CTL clones is growing continuously. ${ }^{60,61,67,68}$ In various cancer patients bearing the appropriate MHC haplotypes, however, an important number of CTL clones is directed against peptides from molecules (MAGE, BAGE, GAGE and RAGE gene family) of the so-called 'cancer testis' antigen group. ${ }^{53,54,66}$ These peptides are able not only to stimulate CTL specific to melanoma cells in vitro ${ }^{69-71}$ but also to induce tumour regression in vivo. ${ }^{72-74}$ Another group of antigenic peptides recognised by a large number of CTL clones from melanoma patients ${ }^{74-78}$ derives from TSDAs (Pmel-17/gp100, MART-1/Melan-A, tyrosinase, and tyrosinase-related proteins, TRP-1 and 2) that are also expressed in normal melanocytes. ${ }^{79}$ The role of CTL against these 'autoantigenes' in melanoma rejection is not clear. However, sometimes a depigmentation, a 
so-called vitiligo, can be observed in treated melanoma patients. The observed depigmentation which is probably caused by destruction of normal melanocytes and the reported association of vitiligo with prolonged survival and spontaneous tumour regression support a possible role of anti-TSDA CTL in tumour regression ${ }^{5,54}$ Most of the melanoma antigenic peptides characterised until now are restricted to HLA-A1, HLA-A2 or HLA-A31 molecules, ${ }^{53,54,58}$ expressed in about $26 \%, 44 \%$ or $6 \%$ of Caucasian melanoma patients, respectively. ${ }^{78,80}$ Therefore, clinical applications of antigenic peptides for tumour vaccination or therapy monitoring (eg by ELISPOT) are limited to patients of these MHC haplotypes. ${ }^{69,73,74,76,81.82}$ The first attempts to immunise melanoma patients with MAGE1, MAGE-3, tyrosinase, gp-100 or MART-1 peptides showed objective tumour regression in a few patients. In some cases the clinical response was accompanied by the presence of peptide-specific CTL in the blood. ${ }^{69.76,81,83.84}$ A more 'MHC-independent', melanoma-specific vaccination was obtained in a more recent study, ${ }^{73}$ using autologous dendritic cells (DC) pulsed with tumour cell extracts, supported by an additional 'non-specific' CD4 helper cell stimulation with keyhole limpet haemocyanin (KLH) which resulted in objective clinical responses in $5 / 16$ patients. The tumour regression was accompanied by a peripheral immune response, as detected by delayed-type hypersensitivity skin reaction to melanoma peptide or tumour cell lysate pulsed DCs. ${ }^{73}$ The application of somatic cell hybrids $(\mathrm{SCH})^{85-87}$ of syngenic or autologous tumour cells with professional APCs (dendritic cells, $\mathrm{M} \Theta$, or activated $\mathrm{B}$-cells) ${ }^{88}$ has been recently applied in rat and mouse tumour models as another successful therapeutic approach for a more 'MHCindependent' vaccination. ${ }^{85-86}$

A third way, the combination of 'non-specific' (eg IL-2 supported) stimulation and specific vaccination (gp-100 peptide) also resulted in objective cancer responses but was accompanied by decreased circulating CTL in the blood of $13 / 31$ patients. $^{74}$ This disappearance of peripheral CTL was explained by their possible invasion of tumour sites. In contrast to the other vaccination strategies, a clinical response to this treatment, however, was only found in those patients who had also received systemic IL-2, indicating synergistic effects of the two components. Together with the results of our phase I study, these data support our recently initiated randomised, French-Swiss multicentre phase II trial using two different doses of Vero-
IL-2 cells injected repeatedly in patients with melanoma.

A simultaneous monitoring of the treatment seems to be important for understanding the mechanisms of different treatment strategies. Skin testing, ${ }^{73}$ somatic cell hybrids ${ }^{85,86}$ or the use of autologous antigen presenting cells (APC) pulsed with peptides, tumour extracts or infected with recombinant viruses encoding tumour antigens ${ }^{89,90}$ could become useful tools for monitoring peripheral anti-tumour responses to detect CTL precursor cells recognizing epitopes restricted to various MHC haplotypes in vitro. Additionally, these approaches also allow the detection of MHC class II restricted tumour antigen presentation. ${ }^{84,89,90}$

\section{Immune escape mechanisms}

Induction and detection of T-cell response to tumour antigens, however, is frequently limited by the tumour cells themselves. Malignant transformation is often associated with genetic alterations providing tumour cells with mechanisms to escape from immune surveillance leading to selection of less immunogenic tumour cell variants. ${ }^{91-95}$ This can be observed in primary or metastatic tumour lesions in vivo but can also be detected after oncogenic transformation in vitro. At the molecular level, the defective signalling of tumour cells could be attributed to

i) down regulation or loss of major histocompatibility complex (MHC) molecules, ${ }^{96,97}$

ii) alteration of antigen processing pathways, resulting in an inability to present tumour-specific antigens to $\mathrm{T}$ cells, ${ }^{98.99}$

iii) absence of costimulatory or adhesion molecules that are essential for activation of the host immune system, ${ }^{1001,101}$ or

iv) production of factors modifying host immune responses. ${ }^{102}$

Presentation of antigenic peptides on MHC class I or II molecules is essential for induction or reactivation of a specific immune response ${ }^{50,103-106}$ Downregulation or loss of certain MHC haplotypes or melanoma antigens enables tumour cells to escape immune surveillance. ${ }^{107-109}$ Therefore, an altered expression of these molecules might represent an important parameter restricting the chances of a successful gene/immune therapy. ${ }^{1(17,110,111}$ However, the opposite might also be true. A partial human leukocyte antigen (HLA) loss 
can lead to tumour cell killing by KIR expressing CTL if the loss-variant downregulates respective $\mathrm{MHC}$ molecules (eg HLA-Cw7) recognised by the KIR (eg p58.2), whereas original tumour cells will not be lysed. ${ }^{39}$ The analysis of the involved mechanisms, eg $\beta 2 \mathrm{M}$ loss, 'defective' expression of transporter associated with antigen presentation (TAP) or proteasome subunits, ${ }^{94,109.110,112}$ will also show whether reversible (eg by IFN $\gamma$ stimulation) or irreversible changes in the tumour cells are responsible for defective tumour antigen expression. ${ }^{94.109 .110 .112}$

\section{Outlook}

Immune therapy is one possibility of cancer treatment. Since the detection of tumour-specific or associated antigens in spontaneous human tumours, rapidly progressing strategies to treat cancer patients have been developed. Successful treatment of patients, however, is furthermore narrowed by our limited understanding of relationships between the components of the immune system and tumour cells. In the case of gene therapy, in 1996, experts of the US Department of Health, NIH, evaluated results of the first 7 years of treatment. In conclusion, they noted that gene therapy has been a feasible and until now also very safe treatment, but unequivocal proof of clinical efficacy failed in many of the more than 100 clinical trials. The most important consequence of the report was the request to 'go back to the bench' as well as to develop more effective viral and non-viral gene therapy vectors. In the meantime more than 300 clinical protocols with more than 3000 patients are open worldwide but the assessment of the situation has not changed dramatically. The main problems are still the failure of vectors to transduce efficiently their targets in vivo, the lack of tumour specificity of available application systems, the increasing switch-off of transcription elements in vivo, even after successful transfer of the transgenes, and the incomplete understanding of the molecular pathology of tumour development and progression.

W French Anderson, one of the pioneers of gene therapy expects the first unequivocal clinical results within the next 5 years, most probably in the field of genetic originative diseases. ${ }^{2}$ In the same period the first tumour-specific vectors will be applied in clinical practice and tissue-specific expression of transgenes will be realised. Among others, one result of the terminated 'Human Genome Project' will be an exponential growth of various gene therapy studies in the subsequent decade. At the end of this period, the first intraveneous applicable vectors will be used in clinical practice, resulting in an efficient expression of transgenes in a sufficient number of tumour cells. When induction of tumour remission by gene or immune therapy will be possible remains speculation. Probably gene and/or immune therapy at most will act as part of a multimodal strategy in oncological therapy, combining surgical, radiotherapeutical, cytostatical and other strategies.

\section{References}

1 Sobol RE, Scanlon KJ (eds). The Internet Book of Gene Therapy. Appleton \& Lange: Stamford, CT 1998. http:/ /www.appleton-lange.com/gentherapy.

2 Anderson WF. Human gene therapy. Nature 1998; 392: 25-30.

3 Gage FH. Cell therapy. Nature 1998; 392: 18-24.

4 Gewirtz AM. The c-myb proto-oncogene: a novel target for human gene therapy. Cancer Treat Res 1996; 84: 93-112.

5 Nielsen LL, Maneval DC. p53 tumoursuppressor gene therapy for cancer. Cancer Gene Ther 1998; 5: 52-63.

6 Wiechen K, Zimmer C, Dietel M. Selection of high activity c-erbB-2 ribozyme using a fusion gene of c-erbB2 and the enhanced green fluorescent protein. Cancer Gene Ther 1998; 5: 45-51.

7 Schuler $\mathrm{M}$ et al. A phase I study of adenovirus mediated wild type p53 gene transfer in patients with advanced non-small cell lung cancer. Hum Gene Ther 1998; 9: 2075-2082.

8 Rosolen A et al. In vitro and in vivo antitumour effects of retrovirus-mediated herpes simplex thymidine kinase gene-transfer in human medulloblastoma. Gene Ther 1998; 5: 113-120.

9 Aghi M, Kramm CM, Chou TC, Breakefield XO, Chiocca EA. Synergistic anticancer effects of ganciclovir/ thymidine kinase and 5-fluorocytosine/cytosine deaminase gene therapies. $J$ Natl Cancer Inst 1998; 90: 370-380.

10 Dunbar CE et al. Retrovirally marked CD34-enriched peripheral blood and bone marrow cells contribute to long-term engraftment after autologous transplantation. Blood 1995; 85: 3048-3057.

11 Goncalves F, Dubart A, Lacout C, Vainchenker W, Dumenil D. Stromal cells maintain the radioprotective capacity of CFU-S during retroviral infection. Gene Ther 1996; 3: 761-768.

12 Roth C, Rochlitz CF, Kourilsky P. Immune response against tumours. Adv Immunol 1994; 57: 281-351.

13 Viret C, Lindemann A. Tumour immunotherapy by vaccination with cytokine gene transfected cells. Intern Rev Immunol 1997; 14: 193-212.

14 Panelli MC, Marincola FM. Immunotherapy update: From interleukin-2 to antigen-specific therapy. In: Perry MC (ed). ASCO Educational Book, American Society of Clinical Oncology 34th Annual Meeting, 1998; pp 467-473. 
15 de Kernion JB, Sarna G, Figlin R, Lindner A, Smith RB. The treatment of renal cell carcinoma with human leukocyte alpha-interferon. $J$ Urol 1983; 130: 1063-1066.

16 Bindon $\mathrm{C}$ et al. Clearance rates and systemic effects of intravenously administered interleukin 2 (IL-2) containing preparations in human subjects. Br J Cancer 1983; 47 : 123-133.

17 Colombo MP, Modesti A, Parmiani G, Forni G. Local cytokine availability elicits tumour rejection and systemic immunity through granulocyte T-lymphocyte cross-talk. Cancer Res 1992; 52: 4853-4857.

18 Bubenik $\mathbf{J}$ et al. Local administration of cells containing aninserted IL-2 gene and producing IL-2 inhibits growth of human tumours in nu/nu mice. Immunol Lett 1988; 19: 279-282.

19 Fearon ER et al. Interleukin-2 production by tumour cells bypasses $\mathrm{T}$ helper function in the generation of an antitumour response. Cell 1990; 60: 397-403.

20 Gansbacher B et al. Interleukin 2 gene transfer into tumour cells abrogates tumourigenicity and induces protective immunity. J Exp Med 1990; 172: 1217-1224.

21 Ley V, Langlade-Demoyen P, Kourilsky P, Larsson-Sciard EL. Interleukin 2-dependent activation of tumour-specific cytotoxic $\mathrm{T}$ lymphocytes in vivo. Eur I Immunol 1991; 21: 851-854.

22 Allione A et al. Immunizing and curative potential of replicating and nonreplicating murine mammary adenocarcinoma cells engineered with interleukin (IL)-2, IL-4, IL-6, IL-7, IL-10, tumour necrosis factoralpha, granulocyte-macrophage colony-stimulating factor, and gammainterferon gene or admixed with conventional adjuvants.. Cancer Res 1994; 54: 6022-6026.

23 Rosenthal FM, Zier KS, Gansbacher B. Human tumour vaccines and genetic engineering of tumours with cytokine and histocompatibility genes to enhance immunogenicity. Curr Opin Oncol 1994; 6: 611-615.

24 Mertelsmann $\mathrm{R}$ et al. Pilot study for the evaluation of T-cell-mediated tumour immunotherapy by cytokine gene transfer in patients with malignant tumours. $J \mathrm{Mol}$ Med 1995; 73: 205-206.

25 Stoppacciaro A et al. Genetic modification of a carcinoma with the IL-4 gene increases the influx of dendritic cells relative to other cytokines. Eur J Immunol 1997; 27: 2375-2382.

26 Cayeux $\mathrm{S}$ et al. Lack of correlation between rejection of tumour cells co-expressing interleukin-2 and B7.1 and vaccine efficiency. Eur J Immunol 1997; 27: 1657-1662.

27 van Elsas A et al. Transfection of IL-2 augments CTL response to human melanoma cells in vitro: immunological characterization of a melanoma vaccine. $J$ Immunother 1997; 20: 343-353.

28 Schmidt W et al. Cancer vaccines: the interleukin 2 dosage effect. Proc Natl Acad Sci USA 1995; 92: $4711-4714$.

29 Sobol RE et al. Injection of colon carcinoma patients with autologous irradiated tumour cells and fibroblasts genetically modified to secrete interleukin-2 (IL-2): a phase I study. Hum Gene Ther 1995; 6: 195-204.

30 Zier KS, Gansbacher B. IL-2 gene therapy of solid tumours: an approach for the prevention of signal transduction defects in T cells. $J$ Mol Med 1996; 74: 127-134.
31 Arienti $\mathrm{F}$ et al. Limited antitumour $\mathrm{T}$ cell response in melanoma patients vaccinated with interleukin-2 genetransduced allogeneic melanoma cells. Hum Gene Ther 1996; 7: 1955-1963.

32 Mackensen A et al. Induction of tumour-specific cytotoxic $\mathrm{T}$ lymphocytes by immunization with autologous tumour cells and interleukin-2 gene transfected fibroblasts. J Mol Med 1997; 75: 290-296.

33 Rochlitz CF et al. Gene therapy study of cytokinetransfected xenogenic cells (Vero-IL2) in patients with metastatic solid tumours. Cancer Gene Ther 1999; 6(3) (in press)

34 Cavallo $\mathrm{F}$ et al. Role of neutrophils and $\mathrm{CD}^{+} \mathrm{T}$ lymphocytes in the primary and memory response to nonimmunogenic murine mammary adenocarcinoma made immunogenic by IL-2 gene. J Immunol $1992 ; 149$; $3627-3635$

35 Hock $\mathrm{H}$ et al. Mechanisms of rejection induced by tumour cell-targeted gene transfer of interleukin 2, interleukin 4, interleukin 7, tumour necrosis factor, or interferon gamma. Proc Natl Acad Sci USA 1993; 90: 2774-2778.

36 Emtage PC, Wan Y, Bramson JL, Graham FL, Gauldie J. A double recombinant adenovirus expressing the costimulatory molecule B7-1 (murine) and human IL-2 induces complete tumour regression in a murine breast adenocarcinoma model. $J$ Immunol 1998; 160: 2531-2538.

37 DeSilva DR, Feeser WS, Tancula EJ, Scherle PA. Anergic $\mathrm{T}$ cells are defective in both jun $\mathrm{NH} 2$-terminal kinase and mitogen-activated protein kinase signalling pathways. $J$ Exp Med 1996; 183: 2017-2023.

38 Roth $\mathrm{C}$ et al. Inhibition of tumour growth by histoincompatible cells expressing interleukin-2. Int Immunol 1992; 4: 1429-1436.

39 Ikeda $\mathrm{H}$ et al. Characterization of anantigen that is recognized on a melanoma showing partial HLA loss by CTL expressing an NK inhibitory receptor. Immunity 1997; 6: 199-208.

40 Paul P et al. HLA-G expression in melanoma: a way for tumour cells to escape from immunosurveillance. Proc Natl Acad Sci USA 1998; 95: 4510-4515.

41 Lode HN et al. Natural killer cell-mediated eradication of neuroblastoma metastases to bone marrow by targeted interleukin-2 therapy. Blood 1998; 91: 1706-1715.

42 Quintin-Colonna F et al. Gene therapy of spontaneous canine melanoma and feline fibrosarcoma by intratumoural administration of histoincompatible cells expressing human interleukin-2. Gene Ther 1996; 3: 1104-1112.

43 Cohen $\mathrm{R}$ et al. Approaches to anti-tumour immunotherapy in mouse and humans. In: Gachelin G, Yikawa $Y$, Ishii S, Kourilsky P, Yaniv M (eds). Genes for development cell growth and infectious diseases. John Libbey Eurotext: Paris, 1995; pp 227-236.

44 Tepper RI, Pattengale PK, Leder P. Murine interleukin-4 displays potent anti-tumour activity in vivo. Cell 1989; 57: 503-512.

45 Tepper RI, Coffman RL, Leder P. An eosinophildependent mechanism for the antitumour effect of interleukin-4. Science 1992; 257: 548-551. 
46 Porgador A et al. Interleukin-6 gene transfection into Lewis lung carcinoma tumour cells suppresses the malignant phenotype and confers immunotherapeutic competence against parental metastatic cells. Cancer Res 1992; 52: 3679-3686.

47 Connor $\mathrm{J}$ et al. Regression of bladder tumours in mice treated with interleukin-2 gene-modified tumour cells. $J$ Exp Med 1993; 177: 1127-1134.

48 Dranoff $\mathrm{G}$ et al. Vaccination with irradiated tumour cells engineered to secrete murine granulocyte-macrophage colony-stimulating factor stimulates potent, specific, and long-lasting anti-tumour immunity. Proc Natl Acad Sci USA 1993; 90: 3539-3543.

49 Tahara H, Lotze MT. Antitumour effects of interleukin12 (IL-12): applications for the immunotherapy and gene therapy of cancer. Gene Ther 1995; 2: 96-106.

50 Zinkernagel RM, Doherty PC. Restriction of in vitro $\mathrm{T}$ cell-mediated cytotoxicity in lymphocytic choriomeningitis within a syngeneic or semiallogeneic system. Nature 1974; 248: 701-702.

51 Townsend AR et al. The epitopes of influenza nucleoprotein recognized by cytotoxic T-lymphocytes can be defined with short synthetic peptides. Cell 1986; 44: 959-968.

52 Traversari $\mathrm{C}$ et al. A nonapeptide encoded by human gene MAGE-1 is recognized on HLA-A1 by cytolytic T lymphocytes directed against tumour antigen MZ2-E. $J$ Exp Med 1992; 176: 1453-1457.

53 Rosenberg SA. Cancer vaccines based on the identification of genes encoding cancer regression antigens. Immunol Today 1997; 18: 175-182.

54 Boon T, Coulie PG, Van den Eynde B. Tumour antigens recognized by $\mathrm{T}$ cells. Immunol Today 1997; 18: 267-268.

$55 \mathrm{Cox} \mathrm{AL}$ et al. Identification of a peptide recognized by five melanoma-specific human cytotoxic $\mathrm{T}$ cell lines. Science 1994; 264: 716-719.

56 Jung S, Schluesener HJ. Human T lymphocytes recognize a peptide of single point-mutated, oncogenic ras proteins. $J$ Exp Med 1991; 173: 273-276.

57 Sahin U, Tureci O, Pfreundschuh M. Serological identification of human tumour antigens. Curr Opin Immunol 1997; 9: 709-716.

58 Jäger E et al. Simultaneous humoral and cellular immune response against cancer-testis antigen NY-ESO-1: definition of human histocompatibility leukocyte antigen (HLA)-A2-binding peptide epitopes. J Exp Med 1998; 187: $265-270$.

59 Skipper J, Stauss HJ. Identification of two cytotoxic T lymphocyte-recognized epitopes in the Ras protein. $J$ Exp Med 1993; 177: 1493-1498.

60 Wölfel $\mathrm{T}$ et al. Ap16INK4a-insensitive CDK4 mutant targeted by cytolytic $\mathrm{T}$ lymphocytes in a human melanoma. Science 1995; 269: 1281-1284.

61 Ressing ME et al. Human CTL epitopes encoded by human papillomavirus type 16 E6 and E7 identified through in vivo and in vitro immunogenicity studies of HLA-A0201-binding peptides. J Immunol 1995; 154: 5934-5943.

62 De Plaen E et al. Structure, chromosomal localization, and expression of 12 genes of the MAGE family. Immunogenetics 1994; 40: 360-369.
63 Takahashi K, Shichijo S, Noguchi M, Hirohata M, Itoh K. Identification of MAGE-1 and MAGE-4 proteins in spermatogonia and primary spermatocytes of testis. Cancer Res 1995; 55: 3478-3482.

64 Lethé B, van der Bruggen P, Brasseur F, Boon T. MAGE1 expression threshold for the lysis of melanoma cell lines by a specific CTL. Melanoma Res 1997; 7: (Suppl.2) S83-S88.

65 Fisk B, Blevins TL, Wharton JT. Ioannides CG Identification of an immunodominant peptide of HER-2/neu proto oncogene recognized by ovarian tumour-specific cytotoxic T lymphocyte lines. $J$ Exp Med 1995; 181: 2109-2117.

66 Van den Eynde BJ, van der Bruggen P. T cell defined tumour antigens. Curr Opin Immunol 1997; 9: 684-693.

67 Robbins PF et al. A mutated beta-catenin gene encodes a melanoma-specific antigen recognized by tumour infiltrating lymphocytes. J Exp Med 1996; 183: 1185-1192.

68 Rubinfeld B et al. Stabilization of beta-catenin by genetic defects in melanoma cell lines. Science 1997; 275: 1790-1792.

69 Mukherji B et al. Induction of antigen-specific cytolytic T cells in situ in human melanoma by immunization with synthetic peptide-pulsed autologous antigen presenting cells. Proc Nat Acad Sci USA 1995; 92: 8078-8082.

70 Rivoltini L et al. Recognition of melanoma-derived antigens by CTL: possible mechanisms involved in downregulating anti-tumour T-cell reactivity. Crit Rev Immunol 1998; 18: 55-63.

71 Tjandrawan $\mathrm{T}$ et al. Autologous human dendriphages pulsed with synthetic or natural tumour peptides elicit tumour-specific CTLs in vitro. I Immunother 1998; 21: 149-157.

72 Uyttenhove $\mathrm{C}$ et al. The expression of mouse gene P1A in testis does not prevent safe induction of cytolytic $\mathrm{T}$ cells against a P1A-encoded tumour antigen. Int $J$ Cancer 1997; 70: 349-356.

73 Nestle FO et al. Vaccination of melanoma patients with peptide- or tumour lysate-pulsed dendritic cells. Nat $\mathrm{Med}$ 1998; 4: 328-332.

74 Rosenberg SA et al. Immunologic and therapeutic evaluation of a synthetic peptide vaccine for the treatment of patients with metastatic melanoma. Nat Med 1998; 4: 321-327.

75 Castelli C et al. Mass spectrometric identification of a naturally processed melanoma peptide recognized by CD8 + cytotoxic T lymphocytes. J Exp Med 1995; 181: 363-368.

76 Jäger $\mathrm{E}$ et al. Cytolytic $\mathrm{T}$ cell reactivity against melanoma-associated differentiation antigens in peripheral blood of melanoma patients and healthy individuals. Melanoma Res 1996; 6: 419-425.

77 Romero $\mathrm{P}$ et al. Cytolytic $\mathrm{T}$ lymphocyte recognition of the immunodominant HLA-A0201-restricted MelanA/MART-1 antigenic peptide in melanoma. $J$ Immunol 1997; 159: 2366-2374.

78 Kittlesen DJ et al. Human melanoma patients recognize an HLA-A1-restricted CTL epitope from tyrosinase containing two cysteine residues: Implications for tumour vaccine development. I Immunol 1998; 160: 2099-2106. 
79 Anichini A et al. Melanoma cells and normal melanocytes share antigens recognized by HLA-A2-restricted cytotoxic $\mathrm{T}$ cell clones from melanoma patients. $J$ Exp Med 1993; 177: 989-998.

80 Bodmer JG et al. Nomenclature for factors of the HLA System, 1996. Hum Immunol 1997; 53: 98-128.

81 Salgaller ML, Marincola FM, Cormier JN, Rosenberg SA. Immunization against epitopes in the human melanoma antigen gp100 following patient immunization with synthetic peptides. Cancer Res 1996; 56: 4749-4757.

82 Scheibenbogen $\mathrm{C}$ et al. Analysis of the $\mathrm{T}$ cell response to tumour and viral peptide antigens by an IFNgammaELISPOT assay. Int $J$ Cancer 1997; 71: 932-936.

$83 \mathrm{Hu} \mathrm{X}$ et al. Enhancement of cytolytic T lymphocyte precursor frequency in melanoma patients following immunization with the MAGE-1 peptide loaded antigen presenting cell-based vaccine. Cancer Res 1996; 56: 2479-2483.

84 Jäger $\mathrm{E}$ et al. Immunoselection in vivo: independent loss of MHC class I and melanocyte differentiation antigen expression in metastatic melanoma. Int J Cancer 1997; 71: 142-147.

85 Guo $\mathrm{Y}$ et al. Effective tumour vaccine generated by fusion of hepatoma cells with activated B cells. Science 1994; 263: 518-520.

86 Gong J, Chen D, Kashiwaba M, Kufe D. Induction of antitumour activity by immunization with fusions of dendritic and carcinoma cells. Nat Med 1997; 3: 558-561.

87 Stuhler G, Walden P. Recruitment of helper T cells for induction of tumour rejection by cytolytic T lymphocytes. Cancer Immunol Immunother 1994; 39: 342-345.

88 Cella M, Sallusto F, Lanzavecchia A. Origin, maturation and antigen presenting function of dendritic cells. Curr Opin Immunol 1997; 9: 10-16.

89 Topalian SL et al. Melanoma-specific $\mathrm{CD}^{+} \mathrm{T}$ cells recognize nonmutated HLA-DR-restricted tyrosinase epitopes. J Exp Med 1996; 183: 1965-1971.

90 Yee $\mathrm{C}$ et al. Isolation of tyrosinase-specific $\mathrm{CD}^{+}$and $\mathrm{CD}^{+} \mathrm{T}$ cell clones from the peripheral blood of melanoma patients following in vitro stimulation with recombinant vaccinia virus. $J$ Immunol 1996; 157: 4079-4086.

91 Uyttenhove C, Maryanski J, Boon T. Escape of mouse mastocytoma P815 after nearly complete rejection is due to antigen-loss variants rather than immunosuppression. I Exp Med 1983; 157: 1040-1052.

92 Marincola FM et al. Loss of HLA haplotype and B locus down-regulation in melanoma cell lines. J Immunol 1994; 153: 1225-1237.

93 Restifo NP et al. Loss of functional beta 2-microglobulin in metastatic melanomas from five patients receiving immunotherapy. J Natl Cancer Inst 1996; 88: 100-108.

94 Seliger B et al. Down-regulation of the MHC class I antigen-processing machinery after transformation of murine fibroblasts. Eur J Immunol 1998; 28: 122-133.

95 Seliger B et al. Analysis of the major histocompatibility complex class I antigen presentation machinery in normal and malignant renal cells: evidence for deficiencies associated with transformation and progression. Cancer Res 1996; 56: 1756-1760.
96 Elliott BE, Carlow DA, Rodricks AM, Wade A. Perspectives on the role of MHC antigens in normal and malignant cell development. Adv Cancer Res 1989; 53: 181-245.

97 Wang Z, Margulies L, Hicklin DJ, Ferrone S. Molecular and functional phenotypes of melanoma cells with abnormalities in HLA class I antigen expression. Tissue Antigens 1996; 47: 382-390.

98 Restifo NP et al. Identification of human cancers deficient in antigen processing. $J$ Exp Med 1993; 177: 265-272.

99 Seliger B, Maeurer MJ, Ferrone S. TAP off - tumours on. Immunol Today 1997; 18: 292-299.

100 Chen $\mathrm{L}$ et al. Costimulation of antitumour immunity by the $\mathrm{B} 7$ counter receptor for the $\mathrm{T}$ lymphocyte molecules CD28 and CTLA-4. Cell 1992; 71: 1093-1102.

101 Townsend SE, Allison JP. Tumour rejection after direct costimulation of $\mathrm{CD}^{+} \mathrm{T}$ cells by $\mathrm{B} 7$-transfected melanoma cells. Science 1993; 259: 368-370.

102 Trojan $\mathrm{J}$ et al. Treatment and prevention of rat glioblastoma by immunogenic C6 cells expressing antisense insulin-like growth factor I RNA. Science 1993; 259: 94-97.

103 Wortzel RD, Philipps C, Schreiber H. Multiple tumourspecific antigens expressed on a single tumour cell. Nature 1983; 304: 165-167.

104 Morrison LA, Lukacher AE, Braciale VL, Fan DP, Braciale TJ. Differences in antigen presentation to $\mathrm{MHC}$ class I and II-restricted Influenza virus-specific cytolytic T lymphocyte clones. I Exp Med 1986; 163: 903-921.

105 Braciale TJ et al. Antigen presentation pathways to class I and class II MHC-restricted T lymphocytes. Immunol Rev 1987; 98: 95-114.

106 Bjorkman PJ et al. The foreign antigen-binding site and T-cell recognition regions of class I histocompatibility antigens. Nature 1987; 329: 512-518.

107 Ostrand-Rosenberg S, Clements VK, Thakur A, Cole GA. Transfection of major histocompatibility complex class I and class II genes causes tumour rejection. $J$ Immunogenet 1989; 16: 343-349.

108 Becker JC, Brocker EB. Lymphocyte-melanoma interaction: role of surface molecules. Recent Results Cancer Res 1995; 139: 205-214.

109 Maeurer MJ et al. Tumour escape from immune recognition: lethal recurrent melanoma in a patient associated with downregulation of the peptide transporter protein TAP-1 and loss of the immunodominant MART1/Malan-A antigen. $J$ Clin Invest 1996; 98: 1633-1641.

110 Hicklin DJ et al. Beta 2-microglobulin gene mutations for immune surveillance. Melanoma Res 1997; 7 (Suppl.): $67-74$.

111 Armstrong TD, Clements VK, Ostrand-Rosenberg S. MHC class II-transfected tumour cells directly present antigen to tumour-specific $\mathrm{CD}^{+} \mathrm{T}$ lymphocytes. $J$ Immunol 1998; 160: 661-666.

112 Sheperd JC et al. TAP1-dependent peptide translocation in vitro is ATP-dependent and peptide-selective. Cell 1993; 74: 577-584. 